\title{
Biosynthesis of Silver Nanoparticles Using Common Sage Extract and Evaluation of Anticancer Activity
}

\author{
Habibeh Zare* \\ Department of Biology, Faculty of Science, Payame-Noor University, Tehran, Iran \\ *Corresponding author: Habibeh Zare, Department of Biology, Faculty of Science, Payame-Noor University, Tehran, Iran
}

\begin{tabular}{|c|c|}
\hline ARTICLE INFO & Abstract \\
\hline Received: 蔧 May 05, 2020 & The aim of the present study is the biosynthesis of silver nanoparticles using \\
\hline Published: 蔧 May 29, 2020 & $\begin{array}{l}\text { the aqueous extract of the common sage (scientific name: salvia officinalis) leaf, and } \\
\text { investigating their antioxidant and antimicrobial activities. In order to synthesize the }\end{array}$ \\
\hline $\begin{array}{l}\text { Citation: Habibeh Zare. Biosynthesis of } \\
\text { Silver Nanoparticles Using Common Sage } \\
\text { Extract and Evaluation of Anticancer } \\
\text { Activity. Biomed J Sci \& Tech Res 28(1)- } \\
\text { 2020. BJSTR. MS.ID.004581. }\end{array}$ & $\begin{array}{l}1 \mathrm{mM} \text { silver nitrate solution. Antioxidant activity of the synthesized nanoparticles was } \\
\text { examined based on the 1-diphenyl-2-picrylhydrazyl (DPPH) radical absorbance, while } \\
\text { the antimicrobial activity of the nanoparticles was evaluated by determining minimum } \\
\text { inhibitory concentration (MIC) against three bacterial species: E. coli } 0157: \mathrm{H} \text { (43895), } \\
\text { S. typhimurium (ATCC } 35987 \text { ), and L. monocytogenes (ATCC 7644). With a spherical } \\
\text { geometry and average particle size of } 30-50 \mathrm{~nm} \text {, the synthesized silver nanoparticles }\end{array}$ \\
\hline $\begin{array}{l}\text { Keywords: Silver Nanoparticles; Common } \\
\text { Sage (Salvia Officinalis); Biosynthesis; } \\
\text { Antimicrobial Activity; Antioxidant Activity }\end{array}$ & $\begin{array}{l}\text { exhibited the maximum absorbance at } 430 \mathrm{~nm} \text {. In this study, the manufactured silver } \\
\text { nanoparticles were used as inhibitory agents for the DPPH radicals (IC50 = } 170 \mu \mathrm{M} \text { ). } \\
\text { The MIC of the silver nanoparticles against the experimental pathogens was found to } \\
\text { range from } 3.6 \text { to } 12.25 \mu \mathrm{g} / \mathrm{mL} \text {. Among other pathogens, the monocytogenes exhibited } \\
\text { the highest value of MIC. The obtained results indicated suitable antioxidant and } \\
\text { antibacterial activities of the biosynthesized nanoparticles. }\end{array}$ \\
\hline
\end{tabular}

\section{Introduction}

The oxidative stress is a result of misbalance between the production of free radicals and the metabolism reactions that end up damaging the lipids, proteins, and nucleic acids. Such damages may arise due to either low level of antioxidants or excessive production of free radicals in the body. In human beings, the oxidative stress is associated with the emergence of chronic diseases such as diabetes and cancer. Accordingly, the production of synthetic and naturally occurring antioxidants is necessary to prevent the oxidative stress and its adverse impacts. The antioxidants can effectively attenuate the adverse impacts of the free radicals in the biologic system and foodstuff via number of different mechanisms, thereby contributing to detoxification. In this respect, one can use the nanoparticles with antioxidant effects that are synthesized through green synthesis method (where plant sublayers are used to prepare environmentfriendly nanoparticles, including no harmful chemical compound). Currently, the use of non-toxic precursors for the synthesis of nanoparticles is largely regarded for preventing biological hazards, especially in medical and pharmaceutical applications, so that many researchers are focused on the active biomaterials obtained from plants or other sources such as bacterial, fungi, and yeasts for the synthesis of nanoparticles. The green synthesis method is believed to enhance the biocompatibility and performance of metal nanoparticles for biological applications thanks to the elimination of the adverse chemical compounds.

When it comes to the biosynthesis of the nanoparticles, it is more advantageous to do that in an extracellular fashion using plants or their extracts, as this synthesis process can be controlled to obtain nanoparticles of particular particle size, particle size distribution, and particle geometry for specific applications. As of present, biosynthesis of silver nanoparticles has been undertaken with various plants, including Acalyphaindica [1], Artemisia nilagirica [2], Ocimum sanctum [3], Piper longum [4], Azadinachta indica, Catharanthus roseus [5], and many others. Moreover, various reports have highlighted the biological characteristics of the biosynthesized silver nanoparticles including antimicrobial, antioxidant [6], and anticancer effects. The studies on the antioxidant 
effects of the silver nanoparticles obtained from various plant species (e.g. Canthium coromandelicum, Terminalia, Rosmarinus officinalis, Syzygium cumini (L.), Cassia, Dalbergia rostrate, and Fraxinus excelsior fistula) have confirmed the antioxidant activity of the silver nanoparticles. Resistance to human pathogens is a major challenge in the pharmaceutical and medical applications. This antibiotic resistance together with excessive and consistent use of chemical drugs contribute to the resistance of the microorganisms. Another disadvantage of using these drugs has been their increased side-effects of them that may cause parasites and/or recurrence of Multidrug-Resistant Pathogens (MRDs) of the diseases that are even more dangerous than the initial disease [7-10].

Accordingly, modification of antibacterial compounds to improve their antibacterial potentials has been an important and priority sector of the research in recent years. The silver has long been acknowledged for its antibacterial activity. Releasing silver ions, the silver nanoparticles exhibit antibacterial effect against both aerobic and anaerobic bacteria. The silver nanoparticles represent colonies of silver atoms with a final diameter of $100 \mathrm{~nm}$. These can enter the bacteria by getting attached to the sulfur-bearing proteins on the surface of the membrane of the bacteria, where they trigger changes in the morphology, membrane permeability, and the cellular respiration and reproduction chain, leading to a cell death. Indeed, the main reason behind the widespread use of silver nanoparticles is their antibacterial activity, so that one can come with an antibacterial coating by adding small amounts of these nanoparticles to the coating and hence eliminate the pollution [1014]. So far, silver nanoparticles have been used by various medicinal herbs, including Aegle Acacia leucophloea, Solanum trilobatum, Syzygium marmelos, cumini, Centella asiatica, and Citrus sinensis. Biosynthesis of silver nanoparticles from the common sage extract and evaluation of their antioxidant and antimicrobial activities have been performed in the food industry to retain more of the nutrients along with the original taste and smell while reducing the food spoilage rate, where nanomaterial coatings with antimicrobial and antioxidant effects are utilized.

Khandelwal et al. synthesized the silver nanoparticles using the leaves of Argimone maxican, ending up with 20-nm particles with inhibitory effects against many bacteria and fungi. In their study, Govindaraju et al. undertook the biosynthesis of silver nanoparticles using Solanum torvum and obtained nanoparticles of $14 \mathrm{~nm}$ in diameter and good inhibitory effects against the growth of bacteria such as Pseudomonas, Aspergillus, Staphylococcus aureus, aeruginosa, and Aspergillus niger flavus. Therefore, the present research attempts to evaluate the antioxidant and antimicrobial activity of the silver nanoparticles that are obtained from the aqueous extract of the common sage. Accordingly, should the activities fell in a good range, compared to the other nanoparticles synthesized with plant extracts, one can proceed to complementary research works for actually using these nanoparticles in the modern technologies adopted in the food industry.

\section{Material and Method}

\section{Chemicals and Microorganisms}

All of the chemicals used in this study were prepared at high purities. Silver nitrate salt $\left(\mathrm{AgNO}_{3}\right)$, hydrochloric acid $(\mathrm{HCl})$, and sodium hydroxide $(\mathrm{NaOH})$ were procured from Merck Co (Germany), and the used microorganisms (including E. coli $0157: \mathrm{H}$ (43895), S. typhimurium (ATCC 35987), and L. monocytogenes (ATCC 7644) were obtained from Iranian Research Organization for Science and Technology. Double-distilled water was used for washing and solution preparation.

\section{Preparing the Extract}

The common sage plant was collected from Kashmar (Khorasan Razavi Province, Iran). Upon investigating the herb according to the herbarium at Ferdowsi University (Mashhad, Iran), it was confirmed to be Salvia officinalis. Some leaves of the plat were washed with the double-distilled water and dried in dark at room temperature. The dried leaves were then powdered using an electrical grinder. The so-called soxhlet method was used to obtain the extract for the synthesis of the nanoparticles. The extract was then filtered using a Whatman No. 24 filter paper. In order to remove the suspended particles in the extract completely, the sample was subjected to centrifugation on a Sorvall Superspeed RC2-B (England) at 1000 RPM for 10 minutes [15-20].

\section{Synthesis of the Nanoparticles}

In order to synthesize the silver nanoparticles, $2 \mathrm{~mL}$ of the extract was added to $4 \mathrm{~mL}$ of a $1 \mathrm{mM}$ silver nitrate solution. A color change from light yellow to dark brown indicated the synthesis of the nanoparticles. The process was performed at $\mathrm{pH}=7$ and a temperature of $40^{\circ} \mathrm{C}$

\section{Silver Nanoparticles Characterization}

The color change was objectively observed on the samples. Furthermore, absorbance spectra were measured in the range of 400 - $700 \mathrm{~nm}$ using a Biotech EPOCH (United States) spectrophotometry apparatus. Further characterization was performed using a Philips CM-120 electron scanning microscopy to identify the geometry and size of the synthesized particles [21-23].

\section{Investigation of DPPH Radical Removal Potential}

The respective assay was a modified version of that presented by Johnsona et al. For this purpose, $0.5 \mathrm{~mL}$ of $0.1 \mathrm{mM}$ DPPH was prepared and introduced into $95 \%$ ethanol with $100 \mu \mathrm{L}$ of the solution of the silver nanoparticles synthesized using the common sage extract (i.e. standard solution). The resultant solution was placed in dark at $38^{\circ} \mathrm{C}$ for 31 minutes, followed by reading the absorbance spectra at a wavelength of $518 \mathrm{~nm}$. In order to compare the activity of the silver nanoparticles synthesized from the aqueous extract of the common sage leaves, the reduced glutathione (GSH) standard was used as an IC50 IC standard antioxidant [24-28]. In order to determine the required concentration for inhibiting $50 \%$ 
of the anti-oxidant activity of the silver nanoparticles synthesized from the aqueous extract of the common sage leaves together with the standard solution, experiments were performed at five different concentrations of the nanoparticles and the GSH standard. The experiments were performed in triplicates and average values were reported. The radical elimination percentage was calculated through the following relationship: where the blank absorbance refers to the absorbance of the control solution containing $0 \mathrm{~mL}$ of $0.5 \mathrm{mM}$ DPPH solution and $100 \mu \mathrm{L} 95 \%$ ethanol instead of the silver nanoparticle solution, so that the reaction absorbance indicates the absorbance of the solution containing the silver nanoparticle sample $[29,30]$.

\section{Antibacterial Activity Evaluation Procedure}

In order to investigate antimicrobial activity of the aqueous extract of the common sage, once finished with purification of and solvent removal from the extract, sample solutions of the extract in 5\% dimethyl sulfoxide (DMSO) were prepared at different concentrations $(1.56,3.12,6.25,12.5,25,50$, and $100 \mu \mathrm{g} / \mathrm{L})$ and stored at $4^{\circ} \mathrm{C}$. Once procured from the Iranian Research Organization for Science and Technology, the standard bacteria were stored in freezer. One colony of each strain was cultured in appropriate culture medium and then subjected to characterization assays. The MIC evaluation was performed via Broth micro-dilution method on a sterilized 96-well plate. In brief, firstly, $100 \mu \mathrm{L}$ of the culture from the Muller-Hinton Broth culture medium was loaded into th or wells of the microplate. Then, the first wall in each row was introduced by $10 \mu \mathrm{L}$ of the silver nanoparticle-bearing extract solution, and successively diluted solutions were added to the next walls. Finally, all wells were loaded by $100 \mu \mathrm{L}$ of diluted microbial suspension (0.5 McFarland). After an incubation stage at $37^{\circ} \mathrm{C}$ for 24 hours, the opacity (indicating the bacterial growth) was measured by an ELISA Starfax 2100 microplate reader (England). By definition, the concentration of the most diluted well on which no opacity was observed was reported as the MIC. The pure extract solution was further used as control. In order to evaluate the minimum bactericidal concentration (MBC), the wells with no opacity were separately cultured on the Muller-Hinton culture medium. After 2 hours, the minimum concentration of the silver nanoparticlecontaining extract on which no bacteria could grow was reported as the MBC. Experiments were performed in triplicates and average values were reported.

\section{Statistical Analysis of the Data}

Investigating the antioxidant and antimicrobial activity of the nanoparticles, the results were subjected to one-way analysis of variance (ANOVA) utilizing SPSS ver. 20. Next, average values were compared based on the minimum significant difference (at a confidence level of 5\%) [30-33].

\section{Results and Discussion}

In the synthesis of the silver nanoparticles using the aqueous solution of the common sage leaves, the plant served as a reducing agent and stabilizer. Figure 1 show the color change of the silver nanoparticle solution and the respective UV-vis spectrophotometry spectra. The appearance of the dark brown color upon the reaction with the silver ion provides a clear indication of the reduction of the metal ions and formation of the silver nanoparticles in the medium. Formation of precipitates along with the color change indicates that the manufactured particles are large in size, while a color change without any precipitation reveals that the synthesized particles are so small (favorable). In the present study, the color change occurred with no precipitation. The basic mechanism driving the synthesis of nanoparticles is the reduction of the ions in the salts (i.e. cancelling of the electrical charge). In this research, this process took 30 minutes at $40^{\circ} \mathrm{C}$ to complete, marking the fastness of this methodology and its feasibility at moderate temperatures, rather than high temperatures. The color change of the colloidal silver nanoparticles from yellow to brown is a result of a phenomenon called Plasmon [34-37].

Upon observing the Surface Plasmon Resonance (SPR) of the color change, the synthesis of the nanoparticles was further confirmed by the spectrophotometry studies. Figure 1 shows the results of UV-vis spectrophotometry on the treated aqueous extract of the common sage following the synthesis of the silver nanoparticles. The maximum absorbance peak on the curve obtained for the solution containing the biosynthesized nanoparticles using the aqueous extract of the common sage was observed at a wavelength of $430 \mathrm{~nm}$, indicating successful synthesis of the nanoparticles. Tanks to the particle SPR, the spectrophotometry method can be used to track the synthesis of silver nanoparticles in the plant extract medium. The absorbance peak of the silver nanoparticles occurs at a wavelength of about $430 \mathrm{~nm}$, with possible shifts due to the actual conditions and particle size. The size, geometry, and size distribution of the synthesized solver nanoparticles were investigated on the SEM apparatus. Figure 2 shows an image of the silver nanoparticles recorded by Transmission Electron Microscopy (TEM), providing some information about the morphology and size of the silver nanoparticles, the SEM images show that the obtained nanoparticles were almost entirely spherical, with their size ranging from 30 to $50 \mathrm{~nm}$ on average. Investigations performed in the present research showed that the extract of the common sage leaves offers large potentials for the synthesis of silver nanoparticles. Following the proposed methodology, the nanoparticles could be manufactured in stages, with the process being cost-effective and relatively fast. 


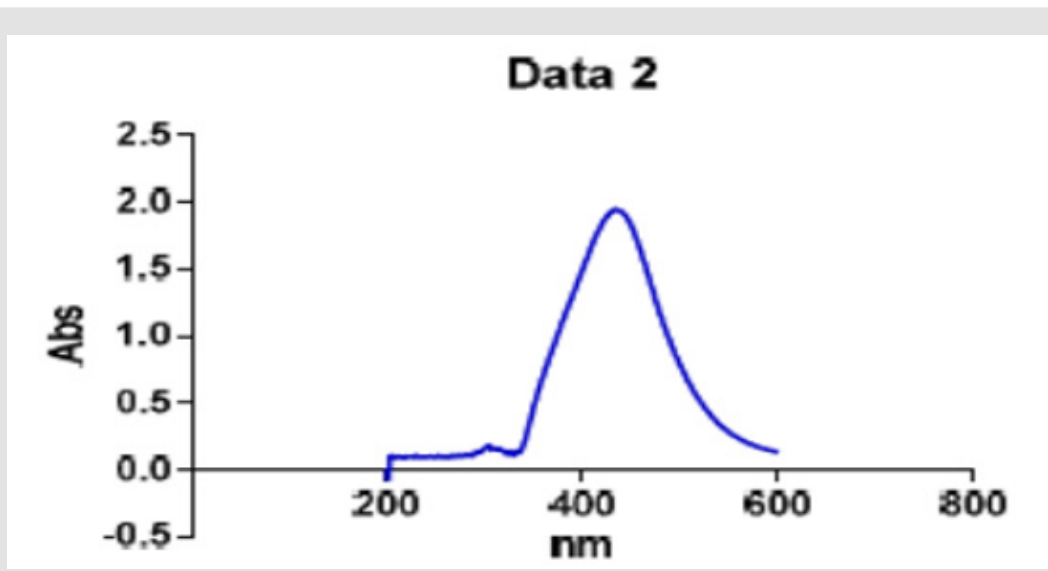

Figure 1: UV-vis spectrum of the silver nanoparticles biosynthesized with the aqueous extract of common sage leaves.

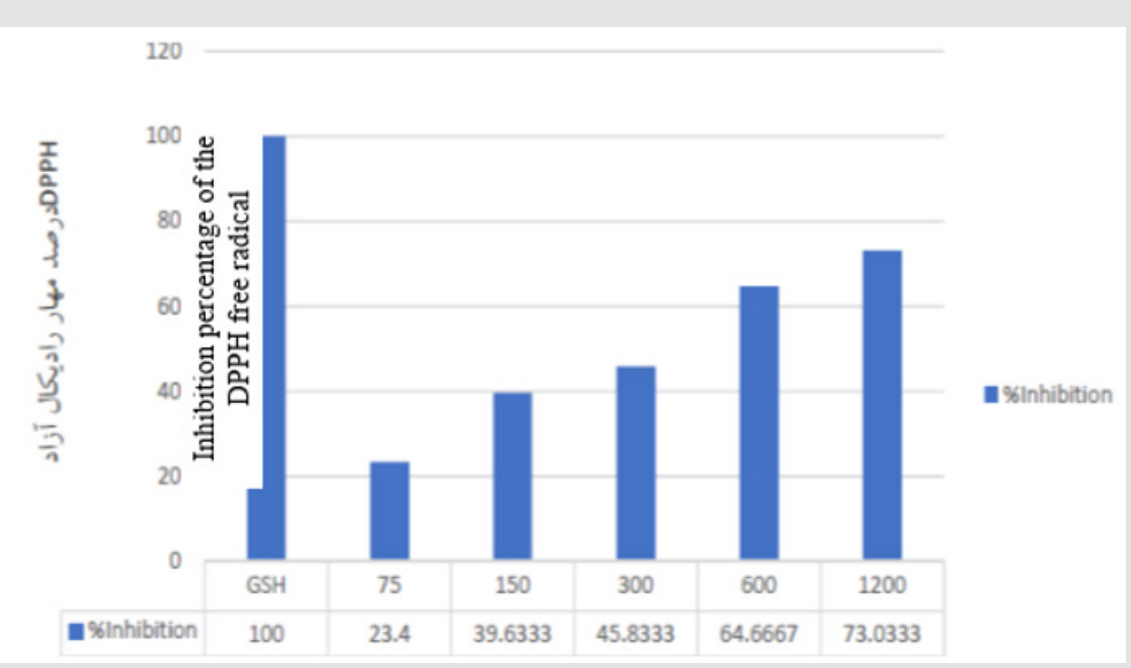

Figure 2: Antioxidant activity of the nanoparticles biosynthesized with the aqueous solution of common sage using the DPPH method, where the GSH is used as a standard. Data are reported in the form of mean \pm standard deviation.

The color change from transparent to brown and the increase in the absorbance of the solution were due to the reducing function of the silver ions and their agglomeration to form the silver nanoparticles. The common sage contains numerous natural compounds including antioxidants, phenols, and flavonoids; all of these compounds effectively contribute to the reduction of the metal ions and their conversion to nano-metric metal atoms and stabilization of the synthesized nanoparticles. In this study, the DPPH radical inhibitory activity of the silver nanoparticles biosynthesized with the aqueous solution of common sage was evaluated by increasing the concentration of the DPPH. Accordingly, it was observed that the radical elimination increased with increasing the concentration of the nanoparticles. As can be seen, some $50 \%$ of the free radicals were inhibited at a nanoparticle concentration of $464 \mu \mathrm{M}$. Particular plants have the potentials for preparing new antioxidant silver nanoparticles via the green methodology. The potential ability of these plants for biosynthesis (reduction) of Ag+ to Ag0 has been identified using spectrophotometry techniques, indicating antioxidant property of the nanoparticles produced via this procedure.
Considering the necessity of identifying both synthetic and naturally occurring antioxidants for preventing the oxidative stress and its adverse impacts, the present research seeks, among other, to characterize the silver nanoparticles synthesized from the aqueous extract of the common sage leaves. In a study performed on the nanoparticles produced using ornamental plants (hyacinthus orientalis 1 . and Dianthus caryophyllus L.), the luminescence-based quantitative methods were used to investigate the antioxidant characteristics of the nanoparticles. Accordingly, the silver nanoparticles exhibited higher levels of antioxidant, as compared to the plant extract alone. Moreover, the nanoparticles of finer particle sizes were found to be more efficient antioxidants that those of coarser particles. In a study, antioxidant activity of the silver nanoparticles produced from the leaf extract of Artemisia annua and Sida acuta was investigated under lab conditions. In this study, the DPPH, as a free radical, received an electron or hydrogen radical to transform into a stable molecule. Reduced absorbance at $517 \mathrm{~nm}$ and the color change from purple to yellow showed that the silver nanoparticles produced from the mentioned plants had the ability to transform the hydrogen into an oxidant, thereby 
exhibiting antioxidant characteristics.

Results of this study further showed that the antioxidant activity of the samples was linked to their concentration, i.e. the antioxidant activity increased with concentration. Compared to standard antioxidant (ascorbic acid), the silver nanoparticles showed very good antioxidant activity. In another study, the antioxidant activity of the silver nanoparticles obtained from the extract of the Chenopodium mural leaves was evaluated using the DPPH assay. Accordingly, the inhibitory power of the nanoparticle was evaluated as $13.27 \pm 0.12$ at a nanoparticle concentration of $5 \mathrm{mg} / \mathrm{L}$ and then increased to $65.43 \pm 0.18$ by increasing the concentration to $20 \mathrm{mg} / \mathrm{L}$. This highlighted that the antioxidant activity is associated with the silver nanoparticles concentration. In another piece of research, antioxidant activity of the silver nanoparticles synthesized from Morinda pubescens was investigated by their inhibitory effects against DPPH, superoxide, and hydroxyl radicals. Based on the DPPH assay, a dosage-dependent color change from purple to yellow with an IC50 of $84 \pm 0.25 \mu \mathrm{g} / \mathrm{mL}$ showed that the sample contained nanoparticles of high antioxidant activity.

In another work, investigations were performed on the antioxidant activity of the silver nanoparticles obtained from the Piper longum fruit using their inhibitory effects against free radicals of DPPH, superoxide, nitric oxide, and hydrogen peroxide. Average inhibitory effect of the silver nanoparticles on the mentioned radicals were evaluated as $67 \%$ at nanoparticle concentrations ranging from $100-600 \mu \mathrm{g} / \mathrm{mL}, 60 \%$ at nanoparticle concentrations ranging from $100-200 \mu \mathrm{g} / \mathrm{mL}, 70 \%$ at nanoparticle concentrations ranging from $50-500 \mu \mathrm{g} / \mathrm{mL}$, and $96 \%$ at nanoparticle concentrations ranging from $10-60 \mu \mathrm{g} / \mathrm{mL}$, respectively. Another study focused on the antioxidant activity of the gold and silver nanoparticles synthesized from the Prunus armeniaca extract. In this study, concentrationdependent antioxidant activity of the nanoparticles was evaluated through DPPH radical and 2,2'-azinobis (3-ethylbenzothiazoline-6sulphonic acid) (ABTS) inhibition assays. Based on the results, IC50 of the gold and silver nanoparticles for the DPPH assay were 11.27 and $16.18 \mathrm{mg}$, and the corresponding values to the ABTS assay were 3.40 and $7.12 \mathrm{mg}$, respectively. That is, the silver nanoparticles showed higher antioxidant activity than the gold nanoparticles. In both cases, an increase in the concentration of the nanoparticles added to their antioxidant activity [38].

The above mentioned studies show that an increase in the concentration of the nanoparticles mixed with different plant extracts results in an antioxidant effect; in some cases, these nanoparticles provided for antioxidant effects resembling or even close to that of standard antioxidants. Similar to the results of the abovementioned studies, the present study shows that the silver nanoparticles biosynthesized from the aqueous extract of the common sage offer good antioxidant effect. Among the pool of naturally occurring metals, the silver ions exhibit intensive antimicrobial effects against many bacterial strains. Compared to the silver ions, the silver nanoparticles can be good antimicrobial agents due to their large specific surface area (surface-to-volume ratio) and unique physiochemical properties. In fact, the main reason behind the largely superior antibacterial effect of the silver nanoparticles over the silver is the large surface-to-volume ratio of the silver nanoparticles, which intensifies the impact of the silver nanoparticles on the bacteria. In this study, once finished with synthesizing the silver nanoparticles, antibacterial activity of the synthesized particles was evaluated against three bacteria, namely Escherichia coli, Listeria monocytogenes, and Salmonella typhimurium. For this purpose, MIC and then MBC of the samples were examined, with the results presented in Table 1 . Table 1 shows that the silver nanoparticles exhibited MIC value of 6.25 - $3.12 \mu \mathrm{g} / \mathrm{mL}$ against the studied pathogens. In addition, the Listeria monocytogenes, among the other bacteria studied in this work, showed the lowest sensitivity to the biosynthesized silver nanoparticles. The two gram-negative pathogens showed a MIC value of $3.12 \mu \mathrm{g} / \mathrm{mL}$. Nevertheless, our studies showed the same value of MBC: $6.25 \mu \mathrm{g} / \mathrm{mL}$.

Table 1: MIC and MBC values of the silver nanoparticles biosynthesized from the aqueous extract of the common sage against four common pathogens found in foodstuff.

\begin{tabular}{|c|c|c|}
\hline Bacterium & MIC $(\boldsymbol{\mu g} / \mathbf{m L})$ & MBC $(\boldsymbol{\mu g} / \mathbf{m L})$ \\
\hline Escherichia coli & 3.12 & 6.25 \\
\hline Listeria monocytogenes & 6.25 & 6.25 \\
\hline Salmonella typhimurium & 3.12 & 6.25 \\
\hline
\end{tabular}

In this study, the biosynthesized silver nanoparticles showed good antioxidant effect against all of the studied pathogens. The results of the MIC and MBC assays highlight the higher value of MIC for the Listeria monocytogenes, as compared to the other pathogens studied in this work, which might be linked to differences in the cell wall between different bacteria. Kim et al. reported that, as a gram-negative bacterium, S. aureus is more resistant to the nanoparticles, as compared to the E. coli. This is while the present study returned the same MBC value for all of the pathogens. It is worth mentioning that antibacterial activity of the nanoparticles depends on the nanoparticle size and concentration. In other reports, Shrivastava et al. (2010) and Guzman et al. (2012) investigated the antibacterial activity of the silver nanoparticles against different bacteria including E. coli, P. aeruginosa, and $S$. aureus. The suggested that although the antibacterial activity is dependent on the concentration, but the effect is more significant for gram-negative bacteria rather than the gram-positive ones. The difference in the response to the silver nanoparticles between the gram-negative and gram-positive bacteria could be attributed to the structural difference between their cell walls. Indeed, the gram-negative bacteria have thinner and hence weaker cell walls, and even more than that, the presence of a negatively-charged extracellular polysaccharide layer facilitates their interaction with the silver nanoparticles that are positively charged. Once a 
nanoparticle is attached to the cell wall, it begins with penetrating through the cell membrane and then interrupts various metabolism and reproduction routes, causing a cell death.

\section{Conclusion}

Results of the present research showed that the common sage leaf extract has large potentials for synthesizing silver nanoparticles, providing a cost-effective yet relatively fast methodology for nanoparticle fabrication. The synthesized nanoparticles exhibited large potentials for reducing the metal ions and converting them to nano-metric metal atoms. According to the obtained results, the synthesized silver nanoparticles could act as a DPPH radical inhibitor (IC50 $=170 \mu \mathrm{m}$ ). Relatively high antioxidant activity of the silver nanoparticles biosynthesized from the aqueous extract of the common sage was further confirmed in this study, so that the MIC value of the silver nanoparticles against the tested pathogens fell in the range of $3.12-6.25 \mu \mathrm{g} / \mathrm{mL}$. In general, the results indicated appropriate antioxidant and antibacterial activities of the biosynthesized nanoparticles.

\section{Acknowledgment}

We would like to kindly appreciate the honorable professors of the Department of Food Science and Technology at Shiraz University.

\section{References}

1. Abdelaziz MS, Shaheen MS, Elnekeety AA, Abdelwahhab MA (2014) Antioxidant and antibacterial activity of silver nanoparticles biosynthesized using Chenopodium murale leaf extract. Journal of Saudi Chemical Society 18(4): 356-363.

2. Ahmed S, Ahmad M, Swami BL, Ikram S (2016) A review on plants extract mediated synthesis of silver nanoparticles for antimicrobial applications: A green expertise. Journal of Advanced Research 7(1): 1728.

3. Bharathi K, Thirumurugan V, Kavitha M, Muruganadam G, Ravichandran K (2014) A comparative study on the green biosynthesis silver nanoparticles using dried leaves of Boerha aviadiffusa L. and Cichorium intybus $L$. with reference to their antimicrobial potential. World Journal of Pharmaceutical Sciences 3: 1415-1427.

4. Bunghez I, Barbinta A, Patrascu M, Badea N, Doncea S, et al. (2012) Antioxidant silver nanoparticles green synthesized using ornamental plants. Journal of Optoelectronics and Advanced Materials 14: 10161022.

5. Buzea C, Pacheco I, Robbie K (2007) Nanomaterials and nanoparticles: Sources and toxicity. Biointerphases 2(4): 17-71.

6. Dauthal P, Mukhopadhyay M (2013) In-vitro free radical scavenging activity of biosynthesized gold and silver nanoparticles using Prunus armeniaca (apricot) fruit extract. Journal of Nanoparticle Research 15 1-11.

7. Elrafie HM, Hamed MA (2014) Antioxidant and anti-inflammatory activities of silver nanoparticles biosynthesized from aqueous leaves extracts of four Terminalia species. Advances in Natural Sciences: Nanoscience and Nanotechnol ogy 5(3): 1-11.

8. Ghaffari Moghaddam M, Hadi Dabanlou R, Khajeh M, Rakhshanipour M, Shameli K (2014) Green synthesis of silver nanoparticles using plant extracts. Korean Journal of Chemical Engineering 31(4): 548-557.
9. Govindaraju K, Tamilselvan S, Kiruthogs G (2010) Simgaravelu, Biogenic silver nanoparicles by Solanum torvum and their promising antimicrobial activity. Journal of Biopesticides 3: 394-399.

10. Guzman M, Dille J, Godet S (2012) Synthesis and antibacterial activity of silver nanoparticles against gram positive and gram negative bacteria. Nanomedicine 8(1): 37-45.

11. Inbathamizh L, Ponnu TM, Mary EJ (2013) In vitro evaluation of antioxidant and anticancer potential of Morinda pubescens synthesized silver nanoparticles. Journal of Pharmacy Research 6(1): 32-38.

12. Jacob SJ, Finub JS, Narayanan A (2012) Synthesis of silver nanoparticles using Piper longum leaf extracts and its cytotoxic activity against Hep-2 cell line. Colloids and surfaces B, Biointerfaces91: 212-214.

13. Jegadeeswaran P, Shivaraj R, Venckatesh R (2012) Green synthesis of silver nanoparticles from extracts of Padina tetrastromatica leaf. Digest Journal of Nanomaterials and Biostructures 7(3): 991-998.

14. Johnsona A, Obota I, Ukponga U (2014) Green synthesis of silver nanoparticles using Artemisia annua and Sida acuta leaves extract and their antimicrobial antioxidant and corrosion inhibition potentials. Journal of Materials and Environmental Science 5(3): 899-906.

15. Khandelwal N, Singh A, Jain D, Upadhyay MK, Verma HN (2010) Green synthesis of silver nanoparticles using Argimone maxicana leaf extract and evaluation of their activity. Digest Journal of Nanomaterials and Biostructures 5(2): 483-489.

16. Kim JS, Kuk E, Yu KN, Kim JH, Park SJ, et al. (2007) Antimicrobial effects of silver nanoparticles. Nanomedicine 3(1): 95-101.

17. Kokila T, Ramesh PS, Geetha D (2016) Biosynthesis of AgNPs using Carica papaya peel extract and evaluation of its antioxidant and antimicrobial activities. Ecotoxicology and Environmental Safety 134: 467-473.

18. Krishnaraj C, Jagan EG, Rajasekar S, Selvakumar P, Kalaichelvan PT (2010) Synthesis of silver nanoparticles using Acalypha indica leaf extracts and its antibacterial activity against water borne pathogens. Colloids and surfaces B, Biointerfaces 76(1): 50-56.

19. Logeswari P, Silambarasan S, Abraham J (2013) Ecofriendly synthesis of silver nanoparticles from commercially available plant powders and their antibacterial properties. Scientia Iranica 20(3): 1049-1054.

20. Mallikarjuna K, Narasimha G, Dillip GR, Praveen B, Shreedhar B (2011) Green synthesis of silver nanoparticles using Ocimum Leaf axtract and their characterization. Digest Journal of Nanomaterials and Biostructures 6(1):181-186.

21. Mittal AK, Kaler A, Banerjee UC (2012) Free radical scavenging and antioxidant activity of silver nanoparticles synthesized from flower extract of Rhododendron dauricum. Nano Biomedicine and Engineering, 4: $118-124$.

22. Moadi T, Ghahramanzadeh R, Yosofi M, Mohammadi F (2014) Synthesis of silver nanoparticles using four species plant and investigation of their antimicrobial activity. Iranian Journal of Chemical Engineering 4: 1-9.

23. Mohan SC, Sasikala K, Anand T, Vengaiah P, Krishnaraj S (2014) Green synthesis antimicrobial and antioxidant effects of silver nanoparticles using Canthium coromandelicum leaves extract. Research Journal of Microbiology 9: 142-150.

24. Murugan K, Senthilkumar B, Senbagam D, Al Sohaibani S (2014) Biosynthesis of silver nanoparticles using Acacia leucophloea extract and their antibacterial activity. International Journal of Nanomedicine 8: 2431-2438.

25. Nazeruddin G, Prasad N, Waghmare S, Garadkar K, Mulla I (2014) Extracellular biosynthesis of silver nanoparticle using Azadirachta indica leaf extract and its antimicrobial activity. Journal of Alloys and Compounds 583: 272-277.

26. Nithya Deva Krupa A, Raghavan V (2014) Biosynthesis of silver nanoparticles using Aegle marmelos (Bael) fruit extract and its 
application to prevent adhesion of bacteria: a strategy to control microfouling. Bioinorganic Chemistry and Applications 10: 1-8.

27. Philip D, Unni C (2011) Extracellular biosynthesis of gold and silver nanoparticles using Krishna tulsi (Ocimum sanctum) leaf. Physica E: Low-dimensional Systems and Nanostructures 43(7): 1318-1322.

28. Ponarulselvam S, Panneerselvam C, Murugan K, Aarthi N, Kalimuthu K (2012) Synthesis of silver nanoparticles using leaves of Catharanthus roseus Linn. G. Don and their antiplasmodial activities. Asian Pacific Journal of Tropical Biomedicine 2(7): 574-580.

29. Rai M, Yadav A, Gade A (2009) Silver nanoparticles as a new generation of antimicrobials. Biotechnology Advances 27(1): 76-83.

30. Reddy NJ, Nagoor Vali D, Rani M, Rani SS (2014) Evaluation of antioxidant, antibacterial and cytotoxic effects of green synthesized silver nanoparticles by Piper longum fruit. Materials Science and Engineering C: Materials for Biological Applications 34: 115-122.

31. Shankar SS, Rai A, Ahmad A, Sastry M (2004) Rapid synthesis of Au, Ag and bimetallic Au core-Ag shell nanoparticles using Neem (Azadirachta indica) leaf broth. Journal of Colloid and Interface Science 275(2): 496502.

32. Shrififar F, Moshafi M, Mansouri S (2007) Invitroevaluation of antibacterial an antioxidant of the essential oil and methanol extract of endemic Zatariamultiflora boiss. Food Control 18(7): 800-805.

ISSN: $2574-1241$

DOI: 10.26717/BJSTR.2020.28.004581

Habibeh Zare. Biomed J Sci \& Tech Res

(C) This work is licensed under Creative

Submission Link: https://biomedres.us/submit-manuscript.php
33. Srivastava S, Bear T, Roy A, Singh G, Ramachandra Rao P (2007) Characterization of enhanced antibacterial effects of novel silver nanoparticles. Nanotechnology 18(22): 103-118.

34. Tarot MB, Masada K, Hosni K, Matzo kB (2010) Changes in fatty acid and essential oil composition of sage (Salvia officinalis L.) leaves under Nalco stress. Food Chemistry 119(3): 951-956.

35. Veerasamy R, Xin TZ, Gunasagaran S, Xiang TFW, Yang EFC, et al. (2011) Biosynthesis of silver nanoparticles using mangosteen leaf extract and evaluation of their antimicrobial activities. Journal of Saudi Chemical Society 15(2): 113-120.

36. Venkatesan J, Kim SK, Shim MS (2016) Antimicrobial, antioxidant, and anticancer activities of biosynthesized silver nanoparticles using marine algae Ecklonia cava. Nanomaterials 6(12): 235-240.

37.Vijayakumar M, Priya K, Nancy FT, Noorlidah A, Ahmed ABA (2013) Biosynthesis, characterization and anti-bacterial effect of plantmediated silver nanoparticles using Artemisia nilagirica. Industrial Crops and Products 41: 235-240.

38. Yugal K Mohanta, S Sujogya KP, Rasu J, Nanaocha S (2017) Antimicrobial, antioxidant and cytotoxic activity of silver nanoparticles synthesized by leaf extract of Erythrina suberosa (Roxb.). Frontiers in Molecular Biosciences 4: 14.

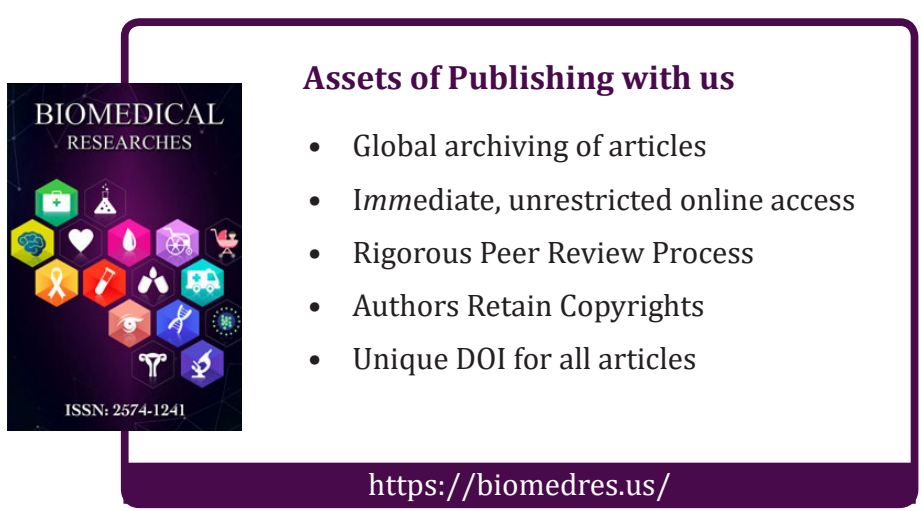

